\title{
Estudo comparativo entre interacionismo sociodiscursivo e linguística sistêmico-funcional
}

\section{Comparative study between socio-discursive interactionism and systemic functional linguistics}

\author{
Aliny Sousa MENDES \\ (Universidade Federal do Tocantins (UFT) - \\ Programa de Pós-Graduação em Letras - Araguaína - TO - Brasil) \\ Wagner Rodrigues SILVA \\ (Universidade Federal do Tocantins (UFT) - \\ Programa de Pós-Graduação em Letras - Palmas - TO - Brasil) \\ Paulo da Silva LIMA \\ (Universidade Federal do Maranhão (UFMA) - São Luís - MA - Brasil. \\ Universidade Federal do Sul e Sudeste do Pará (UNIFESSPA) - Marabá - PA - Brasil)
}

\section{RESUMO}

Apresentamos, neste artigo, um estudo comparativo entre as abordagens teóricas desenvolvidas no Interacionismo Sociodiscursivo (ISD) e na Linguística Sistêmico-Funcional (LSF). Objetivamos identificar as semelhanças elou diferenças entre essas duas correntes teóricas, visto que ambas têm contribuido significativamente para os estudos linguísticos desenvolvidos no Brasil, seja no campo teórico ou aplicado. Embasamonos, principalmente, em Bronckart (2003; 2013), e Halliday e Matthiessen (2014). Os resultados da pesquisa demonstram que há semelhanças entre as duas correntes teóricas na forma como ambas concebem a linguagem, em como veem a linguagem em uso e, também, nas suas concepções de texto. Foram identificadas divergências na forma como as teorias linguísticas abordam a questão de tipo de discurso e gênero textual.

Palavras-chave: Linguística Aplicada; linguagem; gramática; texto. 


\section{ABSTRACT}

We present, in this paper, a comparative study between the theoretical approaches developed in Sociodiscursive Interactionism (ISD) and in Systemic Functional Linguistics (LSF). We aim to identify the similarities and/or differences between these two theoretical currents, since both have contributed significantly to the linguistic studies developed in Brazil, whether in the theoretical or applied field. We are mainly based in Bronckart (2003; 2013) e Halliday and Matthiessen (2014). The results of the research demonstrate that there are similarities between the two theoretical currents in the way they both conceive language, in how they see the language in use, and also in their conceptions of text. Differences have been identified in the way that linguistic theories address the question of type of discourse and textual genre.

Key-words: Applied Linguistics; language; grammar; text.

\section{Introdução ${ }^{1}$}

Neste artigo, apresentamos um estudo comparativo entre as abordagens teóricas de análise linguística desenvolvidas no Interacionismo Sociodiscursivo (ISD) e na Linguística Sistêmico-Funcional (LSF). Nesse sentido, fazemos uma síntese em relação a distintos conceitos implicados entre as duas correntes. Essas teorias são propostas em contraposição aos estudos estruturalistas e prescritivos da língua. A corrente estruturalista, por exemplo, ignora as situações de interação de uso da linguagem. Tratamentos funcionalistas e discursivos dos usos de mecanismos linguísticos podem ser assumidos com propósito de apreender sentidos nos textos examinados.

As duas correntes linguísticas têm servido de embasamento para inúmeros trabalhos desenvolvidos sobre a linguagem, seja em seu aspecto teórico ou aplicado, conforme mostramos em pesquisa realizada em alguns dos principais periódicos brasileiros da Linguística Aplicada (LA). Nesse sentido, identificamos possíveis aproximações entre o ISD e a LSF, fato este que nos incentivou a realizar esta pesquisa, que pode desencadear outras investigações, pois há aspectos das duas teo-

1. Este texto é parte das investigações científicas produzidas no grupo de pesquisa Práticas de Linguagens - PLES (UFT/CNPq). 
rias não focalizados neste artigo. Tal limitação se justifica, inclusive, pelas dimensões deste texto. Salientamos ainda que desconhecemos pesquisas comparativas deste tipo no contexto brasileiro.

Este artigo está organizado em quatro principais momentos, além desta introdução, das considerações finais e das referências bibliográficas. Primeiro, caracterizamos brevemente o campo investigativo não disciplinar da LA. Segundo, mostramos um levantamento preliminar dos usos do ISD e da LSF em pesquisas científicas publicadas em quatro periódicos reconhecidos pela divulgação de investigações produzidas na LA. Terceiro, sintetizamos pressupostos teórico-metodológicos do ISD e da LSF, a exemplo dos conceitos de linguagem, texto, gênero e tipo de discurso. Quarto, apresentamos, finalmente, uma análise comparativa entre algumas categorias analíticas das teorias focalizadas neste texto, destacando, principalmente, semelhanças entre as abordagens propostas.

\section{Linguagem como objeto de investigação na Linguística Aplicada}

Alguns esforços na direção da compreensão da LA revelam o equívoco da redução do referido campo de estudos da linguagem à aplicação de conhecimentos produzidos na Linguística (cf.: Silva et al 2017). Esse fato também se justifica pela semelhança das referidas denominações. Neste artigo, concebemos a LA como um campo não disciplinar de estudos situados da linguagem. Isso significa que os objetos complexos de estudo medeiam práticas sociais contextualizadas e atravessadas por usos da linguagem em diferentes domínios.

Materializados em textos em diferentes suportes, os objetos de pesquisa necessitam de um olhar criterioso, pois as situações de uso da linguagem envolvem atores sociais de origens diversas, os quais não podem ser ignorados na construção e no exame dos dados. Nesse sentido, a LA atravessa as fronteiras disciplinares, não se restringindo ao âmbito dos estudos linguísticos, com propósito de apreender dinâmicas dos fenômenos da linguagem. Ao linguista aplicado, cabe o desafio da busca por teorias que o auxiliem a explicar os fenômenos investigados (cf.: Signorini 1998; Moita Lopes 1998). 
A utilização de conhecimentos produzidos por especialistas ou cidadãos comuns, situados fora do campo investigativo da LA, podendo resultar na ressignificação de pressupostos teóricos e metodológicos de referência, caracteriza a abordagem transdisciplinar da LA. De acordo com Celani (1998: 140-141),

O desenvolvimento de uma atitude transdisciplinar exige disposição natural para ensaiar perspectivas múltiplas, escutar vozes múltiplas. Exige coragem, imaginação, criatividade e iniciativa para uma reestruturação de atitudes, em um estado de incessante interpelação. Mas exige, também, uma reestruturação de organização: novos parceiros, novas concepções, novas abordagens, novas compreensões e novos sistemas. $\mathrm{O}$ que necessariamente exclui os esquemas preestabelecidos. O desenvolvimento de uma atitude transdisciplinar exige, acima de tudo, a disposição para a troca, a ajuda, a cooperação. E aqui está a contribuição para a comunidade, tão condizente com a vocação da Linguística Aplicada.

Essa perspectiva sugere a necessidade de uma revisão das bases epistemológicas características dos percursos de pesquisa, o que aconteceu quando ocorreu a denominada "Virada Linguística Cultural" ou "Virada Crítica" ou, ainda, "Virada Icônica". Nesse momento, na LA, passou-se a compreender que a linguagem é reflexo da sociedade e da cultura; que nossas práticas discursivas são feitas de escolhas e que existem muitos sistemas semióticos na construção de sentidos na contemporaneidade (cf.: Fabrício 2006). Foi nesse momento que aconteceu a "reestruturação de organização" a que já se referia Celani (1998) no excerto reproduzido anteriormente.

Nessa reorganização de pensamento, há o risco de se trocar a tradição por outros regimes semelhantes. Então, segundo Fabrício (2006: 61), para trabalharmos com o conceito de trans, não devemos "fixar nossas teorizações e ideias em essencialismos, homogeneidades ou cristalizações" e podemos ser "mais livres para, exercitando permanentemente nossa capacidade criativa, realizar transformações quando as julgarmos necessárias".

Uma proposta ainda mais dinâmica que a da transdisciplinaridade é a de uma Linguística Aplicada Crítica (LAC) apresentada por Penycook (2001: 4). Segundo o autor, "o aspecto mais importante do trabalho 
crítico é o compromisso com a política crítica das relações sociais"'. O elemento central da LAC é, portanto,

uma forma de explorar a linguagem em contextos sociais que vai além de meras correlações entre a linguagem e a sociedade e, ao invés disso, levanta questões mais críticas que têm a ver com acesso, poder, disparidade, desejo, diferença e resistência (Penycook 2001: 6; tradução nossa) $)^{3}$.

Assim, apropriando-nos das palavras de Gonçalves, Silva e Góis (2014: 13), "na LA, construímos uma ciência que não se limita à elaboração e ao fortalecimento de suas próprias teorias, mas se configura a partir do diálogo com inúmeras vozes sociais".

Um aspecto fundamental para o campo da LA e as duas teorias esboçadas neste artigo é a importância do contexto, elemento responsável pelo conjunto de fatores ou parâmetros socioculturais que exercem influência sobre a forma como um texto é organizado e que, por sua vez, demanda diálogo entre disciplinas ou campos do conhecimento situados fora dos estudos da linguagem. As abordagens do ISD e a LSF também são caracterizadas pelo diálogo com outras disciplinas, conforme observável mais adiante, o que justifica a relevância do uso das referidas teorias para análise linguística dos dados, especialmente em pesquisas situadas na LA.

\section{Pesquisas em Linguística Aplicada com ISD e LSF}

As duas abordagens teóricas focalizadas neste artigo vêm se expandindo significativamente no território brasileiro. Em levantamento preliminar realizado em quatro principais periódicos brasileiros no campo científico da LA, constatamos que, nos últimos dez anos, houve um crescente número de pesquisas que envolvem o ISD e a LSF. Os periódicos investigados foram: Caminhos em Linguística Aplicada -

2. "the most significant aspect of critical work is an engagement with political critiques of social relations" (Penycook 2001: 4).

3. "A central element of critical applied linguistics, therefore, is a way of exploring language in social contexts that goes beyond mere correlations between language and society and instead raises more critical questions to do with access, power, disparity, desire, difference, and resistance" (Penycook 2001: 6). 
CLA(UNITAU); Documentação de Estudos em Linguística Teórica e Aplicada - DELTA (PUC/SP); Revista Brasileira de Linguística Aplicada - RBLA (UFMG); e Trabalhos em Linguística Aplicada - TLA (UNICAMP).

Para identificar os artigos científicos em que o ISD ou a LSF foram utilizados como teoria de análise linguística dos dados examinados, lemos os resumos dos referidos textos disponibilizados nas edições publicadas dos periódicos entre 2007 e 2016 . Ao ser observado o uso de uma das referidas teorias, passamos ao exame das demais seções textuais, com propósito de identificar adequadamente os objetos de pesquisa investigados.

Numa análise quantitativa dos artigos identificados, registramos 97 (noventa e sete) artigos com o uso do ISD ou da LSF. Desse total, 32 (trinta e duas) pesquisas apresentadas utilizaram o ISD e 65 (sessenta e cinco), a LSF. No Quadro 1, listamos as principais temáticas de investigação nos trabalhos científicos identificados.

Quadro 1 - Temáticas investigadas nos periódicos

\begin{tabular}{|c|c|}
\hline $\begin{array}{l}\text { INTERACIONISMO } \\
\text { SOCIODISCURSIVO }\end{array}$ & $\begin{array}{l}\text { LINGUÍSTICA SISTÊMICO- } \\
\text { FUNCIONAL }\end{array}$ \\
\hline \multicolumn{2}{|c|}{ Ensino de línguas } \\
\hline \multicolumn{2}{|c|}{ Formação docente } \\
\hline \multicolumn{2}{|c|}{ Representação de atores sociais } \\
\hline \multicolumn{2}{|c|}{$\begin{array}{l}\text { Análise dos usos de gêneros textuais e seus padrões de realização em diversos } \\
\text { contextos }\end{array}$} \\
\hline Letramento de alunos e professores & Estudo da tradução \\
\hline $\begin{array}{l}\text { Prática profissional (de professores em } \\
\text { formação continuada, professores de pós- } \\
\text { graduação, enfermeiros, entre outros) }\end{array}$ & Produção escrita \\
\hline $\begin{array}{l}\text { Produção textual em ambiente digital/ } \\
\text { virtual }\end{array}$ & Descrição de línguas \\
\hline Ensino/aprendizagem de gramática & $\begin{array}{l}\text { Material didático para ensino de } \\
\text { línguas }\end{array}$ \\
\hline
\end{tabular}

Fonte: autoria própria

Nas primeiras linhas do Quadro 1, elencamos as temáticas trabalhadas a partir do uso das duas teorias abordadas: ensino de linguas; 
formação docente; representação de atores sociais; análise dos usos de gêneros textuais e seus padrões de realização em diversos contextos. Em seguida, expomos as temáticas que aparecem ora no ISD (letramento de alunos e professores; prática profissional - de professores em formação continuada, professores de pós-graduação, enfermeiros, entre outros; produção textual em ambiente digital/virtual; ensino/ aprendizagem de gramática), ora na LSF (estudo das traduções; produção escrita; descrição de línguas; material didático para ensino de línguas). Ao compararmos as ocorrências das temáticas, constatamos aproximações nos objetos de estudo envolvendo as duas teorias focalizadas. As temáticas enfocam a formação de professores, a atuação desses profissionais em sala de aula e os objetos de ensino por eles construídos. Além disso, as duas abordagens teóricas são utilizadas na investigação de usos da linguagem em outras esferas profissionais ou sociais.

\section{Caracterização do Interacionismo Sociodiscursivo}

Para uma síntese a respeito do interacionismo social, partimos do trabalho de Bronckart (2003), ao afirmar que a posição epistemológica denominada de interacionismo social dá origem a diversas correntes filosóficas e das ciências humanas. Em tais campos, é concebida a ideia de que as propriedades específicas das condutas humanas são o resultado de um processo histórico de socialização, viabilizado, principalmente, pela necessidade e pelo estabelecimento de instrumentos semióticos.

Ainda segundo o autor, a investigação interacionista considera a historicidade do ser humano e tem interesse "em primeiro lugar, pelas condições sob as quais, na espécie humana, se desenvolveram formas particulares de organização social, ao mesmo tempo em que (ou sob o efeito de) formas de interação de caráter semiótico" (Bronckart 2003: 22).

O interacionismo é reforçado pela antropologia, pela socioantropologia e por abordagens sociofilosóficas de Habermas (1987) e de Ricoeur (1986). Apesar da contribuição de outros estudiosos notáveis, é a obra de Lev Vygotsky a constituinte do fundamento do interacionismo 
em psicologia. Diferentemente das proposições de outras escolas, para Vygotsky, segundo Bronckart (2003), o homem é tanto um organismo vivo quanto um organismo consciente e a psicologia tem o papel de descrever e explicar esses dois fenômenos. Foi isso que diferenciou o trabalho do psicólogo frente a outras correntes psicológicas. A abordagem vygotskiana se associa mais visivelmente a abordagem interacionista sociodiscursiva.

Vygotsky acreditava que a psicologia deveria considerar que o universo é formado por uma matéria homogênea em ação; que o físico e o psíquico são as únicas propriedades dessa matéria acessíveis à inteligência do homem que, por sua vez, apreende a matéria parcial e descontinuamente dos fenômenos físicos e psíquicos. Tais considerações advêm da epistemologia monista de Spinoza (cf.: Bronckart 2003).

Para o psicólogo, sendo considerada essa epistemologia e a autonomia funcional dos fenômenos psíquicos, a centralidade da psicologia seria a questão "das condições evolutivas e históricas da emergência desse tipo de fenômeno e, em particular, da emergência do pensamento consciente dos organismos humanos" (Bronckart 2003: 26).

Nesse sentido, para o interacionismo social, "a consciência de si e a construção das funções superiores são estreitamente dependentes da história de relações do indivíduo com sua sociedade e da utilização da linguagem" (Dolz \& Schneuwly 2004: 39). Portanto, por pertencer a uma comunidade, o indivíduo compreende e antecipa as atividades do outro, e também permite modificar o seu próprio comportamento de acordo com o ponto de vista do outro.

Para Bronckart (2003:28), a partir da década de 60, quando foi redescoberta, reeditada e traduzida, a obra vigotskiana passou a contribuir para a "renovação teórica e empírica da psicologia do desenvolvimento", o que inspirou e orientou as abordagens sociais da escola de Bernard Schneuwly, renomado pesquisador do ISD. Nesse sentido, no projeto do interacionismo sociodiscursivo, a psicologia precisa levar em consideração as ações humanas em suas dimensões sociais e discursivas.

Baseado em seu pesquisador de maior renome, Jean-Paul Bron- 
por meio de ações de linguagem, ou seja, da produção do discurso que, por sua vez, são responsáveis pela materialização textual. Os textos são a "unidade de ação discursiva por excelência para a teoria" (Chiapinotto 2010: 5). A teoria é, portanto, "uma tentativa contemporânea para continuar a tendência do interacionismo social, cuja figura simbólica é o psicólogo Vygotsky" (Bronckart, 2013: 65; itálico do original).

Bronckart (2006: 9) define o ISD como "teoria sobre o desenvolvimento humano", pois se preocupa com as características discursivas e sociais que constituem o ser humano em suas ações cotidianas. Recebe o nome de Interacionismo Sociodiscursivo por ser proposta para "estudar as condições de emergência e de funcionamento do pensamento consciente, tomando como unidade de análise a ação de linguagem, individual e socialmente situada" (Bork-Gödke 2016: 81).

O questionamento central do ISD é sobre o "papel que a linguagem desempenha, e, mais precisamente, as práticas de linguagem, na constituição e no desenvolvimento das capacidades epistêmicas (ordem dos saberes) e praxeológicas (ordem do agir) dos seres humanos" (Bronckart 2006: 4).

De acordo com Bronckart (2003), a espécie humana é caracterizada pela diversidade e complexidade de sua organização e atividade ${ }^{4}$. Ela tem certa emergência de uma forma de comunicação, nesse caso, expressa pela linguagem, o que "confere às organizações e atividades humanas uma dimensão particular, que justifica que sejam chamadas de sociais" (Bronckart 2003: 31; negrito do original). A interação entre os indivíduos da espécie humana é mediada por interações verbais, tornando o agir comunicativo parte constitutiva do social. Dessa forma, depreendemos que a maior função da linguagem está na ordem comunicativa.

Segundo Bronckart (2013: 65-66), o ISD contemporâneo adota quatro princípios, a saber: (1) há dois fatores determinantes no processo de desenvolvimento das capacidades intelectuais e dos mundos coletivos: o surgimento da linguagem e da história social humana; (2) as dimensões biológicas, psicológicas, sociológicas e linguísticas em

4. A noção de atividade, inspirada em Alexis N. Leontiev (1979), está relacionada ao acesso que os organismos vivos têm ao meio ambiente e à construção de representações sobre o mesmo através das suas organizações funcionais de comportamentos (Bronckart 2003). 
interação constituem o ser humano, portanto, deve haver apenas uma ciência humana integrada; (3) tal ciência deve ter, sólida e profundamente, uma fundamentação filosófica; (4) essa ciência humana deve ser útil à sociedade.

A partir desses princípios, o ISD contemporâneo tenta completar os trabalhos dos históricos fundadores do interacionismo social em três direções. A primeira, embasada em Ferdinand Saussure e Valentin Voloshinov, diz respeito ao "desenvolvimento de uma abordagem mais técnica à linguagem que rejeita firmemente o cognitivismo e/ou perspectivas de Chomsky" (Bronckart 2013: 66) ${ }^{5}$.

A segunda direção refere-se à "contribuição de várias disciplinas não linguísticas que tratam, em primeiro lugar, da organização e funcionamento psicológico (a referência central aqui é Piaget 1970, 1974), e, em segundo lugar, das formas de organização sociológica (com Durkheim 1898, e Habermas 1987, como as principais referências)" (Bronckart 2013: 66) .

Por fim, a terceira direção trata de um compromisso para os problemas educacionais. Tal compromisso "se concretizou mais particularmente em uma metodologia para o ensino de línguas e textos (didática), destinada ao ensino da língua materna" (Bronckart 2013: 66)7.

\section{Caracterização da Linguística Sistêmico-Funcional}

A LSF apresenta um vasto e diversificado desenvolvimento ao redor do mundo. O linguista J. R. Firth foi quem fez as primeiras sistematizações do princípio de que uma das mais significativas manifestações da cultura de um povo é a língua. Tal princípio havia sido introduzido por seu professor, o antropólogo Bronislaw Malinowski, no

5. "First of all, the development of a more technical approach to language, one which firmly rejects the cognitivism and/or Chomskyan perspectives" (Bronckart 2013: 66). 6. "contribution of various non linguistic (SIC) disciplines which deal, first, with psychological organization and functioning (the central reference here is Piaget 1970, 1974), and secondly, with the forms of sociological organization (with Durkheim 1898, and Habermas 1987, as major references)" (Bronckart 2013: 66). ics), intended for native language teaching" (Bronckart 2013: 66). 
início do século XX. A partir da década de 1960, a LSF foi estruturada por Michael Halliday, aluno de J. R. Firth (cf.: Halliday \& Hasan, 2006). A sistematização dessa teoria aparece na sua obra An Introduction to Functional Grammar, em 1985, que foi revista e ampliada em coautoria com Christian M. I. M. Matthiessen, em 2004. A referida obra já se encontra em sua quarta edição publicada em 2014.

A LSF é bastante utilizada na Educação, Linguística e Linguística Aplicada. Tem contribuído não só para análises de textos verbais, a exemplo da descrição de línguas, mas também para o trabalho com textos não verbais, envolvendo a leitura de imagens (cf.: Painter, Martin \& Unsworth 2013). Em diferentes locais, a teoria tem auxiliado na produção de programas de ensino de línguas, incluindo aí práticas de alfabetização, além de programas relacionados à comunicação institucional (cf.: Vian Jr 2003; Silva et al. 2015; Silva \& Silva 2016).

As pesquisas realizadas a partir dos pressupostos da LSF compartilham uma concepção comum de linguagem, a exemplo da reproduzida adiante nos termos de Fuzer e Cabral (2010):

entidade viva, presente em situações, grupos, locais, eventos variados e, como tal, sofre a influência desses e de outros fatores. Como propriedade de comunidades, culturas e indivíduos, a língua é variável, um potencial de significados à disposição dos falantes, que dela fazem uso para estabelecer relações, representar o mundo e, com isso, satisfazer determinadas necessidades em contextos sociais específicos (Fuzer \& Cabral 2010: 5).

A LSF se configura como uma teoria linguística que apreende os textos como unidades de análise, resultantes de escolhas realizadas pelos usuários a partir dos diversos sistemas gramaticais disponibilizados na língua. Em outros termos, a teoria focaliza a língua como formas de interação cujas realizações são motivadas por convenções construídas culturalmente em diferentes domínios sociais. Nas palavras de Barbara e Macêdo (2009: 90), a LSF é compreendida

como uma teoria social porque parte da sociedade e da situação de uso para o estudo da linguagem; seu foco está em entender como se dá a comunicação entre os homens, a relação entre indivíduos e desses com a comunidade. Caracteriza-se também como uma teoria semiótica porque se preocupa com a linguagem em todas as suas manifestações. Procura desvendar como, onde, porque e para que o homem usa a língua, bem como a linguagem em geral, e como a sociedade o faz. 
A unidade de análise da LSF é o texto. Por isso, há a necessidade de uma gramática que explique como o sentido textual é produzido. A gramática recebe o nome de sistêmico-funcional por conceber a língua como sistemas linguísticos em constante relação e por explicar as funções desempenhadas pela linguagem na produção de significados nos textos. As funções da linguagem são denominadas metafunções por possibilitarem a compreensão dos usos gramaticais responsáveis pela constração de discursos sobre mundo por elas representado, conforme detalhes apresentados na seção seguinte.

\section{Semelhanças e diferenças entre o ISD e a LSF}

Na LSF, a língua é constituída por recursos gramaticais com os quais as pessoas constróem representações do mundo exterior e, inclusive, do mundo interior aos próprios pensamentos. Essas construções resultam da interação entre três metafunções da linguagem realizadas simultaneamente nas mais diversas manifestações linguísticas. As metafunções da linguagem são: ideacional; interpessoal; e textual (cf. Halliday 1985; Halliday \& Matthiessen 2014).

A metafunção ideacional é subdividida em duas formas de discursivização do mundo: a metafunção experiencial, que representa a realidade - interna ou externa - do usuário da língua. É realizada a partir do sistema gramatical de TRANSITIVIDADE; e a metafunção lógica, referente à organização lógica da experiência que o falante tem do mundo, através da articulação de palavras, frases e orações no enunciado. É realizada a partir do sistema gramatical TÁTICO e pelo sistema LÓGICO-SEMÂNTICO, conforme descrito em pesquisa brasileira por Silva, Silva e Borba (2016).

A metafunção interpessoal é responsável por sentidos construídos a partir de escolhas gramaticais no sistema de MODO. O exame dessas escolhas linguísticas nos possibilita compreender as relações instauradas ou posições ocupadas pelos atores sociais envolvidos nas interações. A metafunção textual, por sua vez, possibilita a descrição da organização da mensagem na oração, salientando as informações antigas e novas. É realizada a partir do sistema gramatical de TEMA. Ao examinarmos a organização da mensagem na oração, também envolvemos mais diretamente as metafunções ideacional e interpessoal. 
Alguns estudiosos brasileiros definem as metafunções e suas aplicabilidades de forma suscinta. Nas palavras de Fuzer e Cabral (2010: 21), por exemplo, as metafunções são manifestações "no sistema linguístico, dos propósitos que estão subjacentes a todos os usos da língua: compreender o meio (ideacional), relacionar-se com o outro (interpessoal) e organizar a informação (textual)". Vian Jr. e Ikeda (2009: 18) assim as resumem:

Trocamos significados ideacionais, ao mesmo tempo em que interagimos com membros de nosso meio social, o que nos exige fazer escolhas em relação à maneira como vamos nos dirigir à pessoa em função de nossa relação social, incluindo aí relações de hierarquia, afetividade e classe social; logo, estamos trocando também significados interpessoais. Por fim, ao elaborarmos a forma como vamos interagir, seja pelo modo oral, seja pelo escrito, estruturamos a nossa interação de modo a organizar o conteúdo de nossa mensagem, o que nos leva, portanto, a trocar significados textuais.

As três metafunções constituem, portanto, a linguagem em funcionamento. Na Figura 1, representamos sinteticamente a maneira de organização da linguagem, considerando as interferências contextuais para materialização textual a partir de escolhas léxico-gramaticais realizadas por falantes ou escritores a partir de sistemas linguísticos disponibilizados na língua.

Figura 1 - Síntese do Funcionamento da Linguagem (LSF)

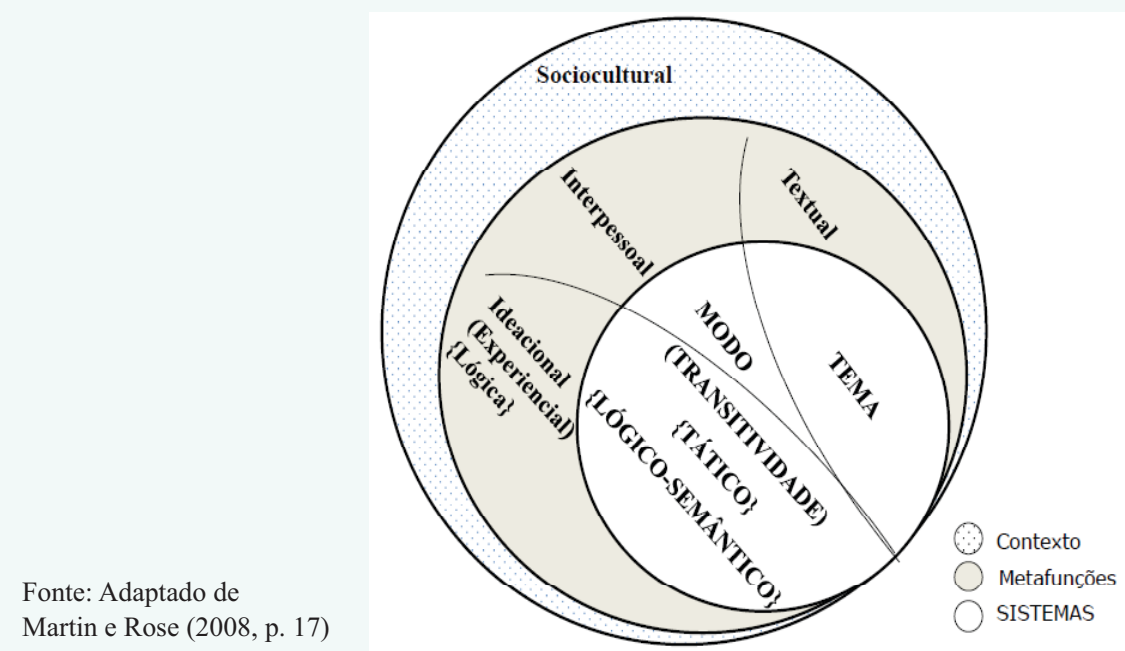


Para o ISD, a linguagem é uma característica primária da atividade humana e tem a função de estabelecer a comunicação entre os indivíduos. Segundo Bronckart (2003), o que o indivíduo produz, em termos de linguagem, é feito em consonância com uma intertextualidade advinda de grupos sociais anteriores. Ou seja, já existe uma acumulação de textos e signos que traz consigo resultados das relações que foram estabelecidas pelas gerações precedentes.

Bronckart (2003) menciona os trabalhos de Berrendonner et al. (1983) para afirmar que as "únicas realidades empiricamente atestáveis das línguas" são os gêneros de textos, uma vez que toda língua tem subsistemas interligados e heterogêneos.

Essa abordagem do ISD sobre linguagem enquanto atividade humana é social. No tocante às dimensões psicológicas dessa abordagem, a unidade de análise adotada para compreender as capacidades envolvidas (mentais e comportamentais) é chamada de ação.

A ação "mobiliza e coloca em interação as dimensões físicas (ou comportamentais) e psíquicas (ou mentais) das condutas humanas" (Bronckart 2003: 40). Isso é o que constitui o objeto cientificamente interpretável da psicologia. Segundo o autor, a tese central do ISD "é que a ação constitui o resultado da apropriação, pelo organismo humano, das propriedades da atividade social mediada pela linguagem" (Bronckart 2003: 42; negrito do original). O autor afirma que a ação humana se apresenta tanto como parte da atividade social quanto como produto da apropriação pelo agente. Esse último é assim denominado por participar das avaliações sociais e julgar o agir de outros indivíduos, atribuindo-lhes capacidades de ação. Melhor dizendo, à intervenção ativa se resume o estatuto de agente.

Sendo social, a atividade de linguagem pode se tornar objeto de avaliações metadiscursivas que, por sua vez, "produzem ações específicas, ou ações de linguagem, atribuíveis a agentes verbais" (Bronckart 2003: 45; negrito do original). Engajados em uma ação de linguagem, os agentes semiotizam o mundo mobilizando referentes (ou conteúdo temático) dessa ação. Para controlar esse processo de semiotização, são mobilizados alguns aspectos representados na Figura 2. 
Figura 2 - Aspectos mobilizados no contexto da ação de linguagem

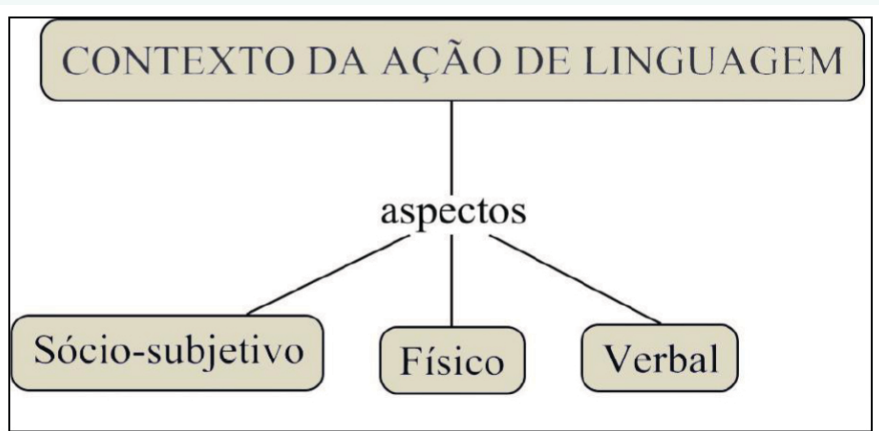

Fonte: Elaborado pelos autores com base nos conceitos apresentados em Bronckart (2003: 47).

Para semantizar um referente, o agente tem à sua disposição várias possibilidades de escolha de signos oferecidas pela língua. Suas escolhas são "representações pessoais referentes às normas sociais e à imagem que convém dar de si mesmo" (Bronckart, 2003: 47). Esse é o aspecto sócio-subjetivo. Para o autor, representações dos parâmetros objetivos da interação verbal constituem o aspecto físico do contexto da ação de linguagem. Essas representações referem-se ao que o agente constrói sobre si mesmo (falante ou escritor), sobre seus possíveis interlocutores e sobre o espaço-tempo de sua ação. Por fim, o aspeto verbal diz respeito aos conhecimentos que o agente traz sobre sua língua e sobre os gêneros de textos em uso. Isso se configura como o conhecimento da intertextualidade.

Bronckart (2013) estabeleceu alguns parâmetros de semelhança entre a LSF e o ISD. Isso talvez seja justificado pela proximidade que os pesquisadores do ISD tiveram com a LSF nos primóridos da elaboração teórica. De acordo com o autor, o ISD teve como base dois textos fundadores da linguística funcional: Halliday, 1967 - Notes on transitivity and theme in English; e Halliday e Hassan, 1976 - Cohesion in English. Com o passar do tempo, perdeu-se o contato com a abordagem sistêmico-funcional da linguagem.

Nesse sentido, Bronckart (2013) elencou algumas características da linguagem que são compartilhadas pelas duas teorias, a saber: "é, fundamentalmente, um sistema semiótico"; "é, principalmente, uma 
atividade"; "é o uso dentro de um contexto social"; "constitui o instrumento da construção de propriedades especificamente humanas"; "deve ser analisada como um sistema, ou melhor, como um sistema de sistemas interconectados" (Bronckart, 2003: 67; grifos do autor) ${ }^{8}$.

Aprofundando um pouco a análise de Bronckart (2013), ousamos estabelecer uma equivalência entre as abordagens do funcionamento da linguagem nas teorias focalizadas neste artigo. No Quadro 2, mostramos uma comparação das semelhanças entre as metafunções da lingugem, na LSF, e os aspectos do contexto da ação de linguagem, no ISD.

Quadro 2 - Linguagem na LSF e no ISD: semelhanças

\begin{tabular}{|l|l|}
\hline \multicolumn{1}{|c|}{ LSF } & \multicolumn{1}{c|}{\begin{tabular}{c}
\multicolumn{1}{c|}{ ISD } \\
METAFUNÇÕES DA LINGUAGEM
\end{tabular}} \\
\hline $\begin{array}{l}\text { Metafunção Ideacional: representação } \\
\text { dos mundos internos e externos. }\end{array}$ & $\begin{array}{l}\text { Aspecto } \text { Sócio-subjetivo: } \text { representações } \\
\text { de si mesmo e das normas sociais. }\end{array}$ \\
\hline $\begin{array}{l}\text { Metafunção Interpessoal: relações entre } \\
\text { o usuário da língua e o interlocutor. }\end{array}$ & $\begin{array}{l}\text { Aspecto fisico: } \text { construções do agente } \\
\text { sobre si mesmo, sobre seus possíveis } \\
\text { interlocutores e sobre o espaço-tempo } \\
\text { da ação. }\end{array}$ \\
\hline $\begin{array}{l}\text { Metafunção textual: escolhas linguísticas } \\
\text { para construção da mensagem. }\end{array}$ & $\begin{array}{l}\text { Aspecto verbal: conhecimentos do } \\
\text { agente sobre sua língua. }\end{array}$ \\
\hline
\end{tabular}

Fonte: elaborado pelos autores

O que é denominado de metafunção ideacional na LSF equivale ao que o ISD chama de aspecto sócio-subjetivo, pois ambos referemse à representação que o usuário da língua faz de seus mundos interno (representação de si mesmo) e externo (normas sociais).

Já a metafunção interpessoal na LSF, que trata das relações entre os usuários da língua e aos papéis que a estes são atribuídos no momento em que a linguagem está em uso, equivale ao aspecto físico do ISD. Apesar de, na descrição apresentada no Quadro 2, parecer que o aspecto físico é mais abrangente por levar em consideração, além dos

8. "Language is, fundamentally, a semiotic system (...)"; "Language is, primarily, an activity; it is usage within a social context"; "Language constitutes the instrument of the construction of specifically human properties"; Language must be analysed as a system, or rather as a system of interlocking systems" (Bronckart 2003: 67; itálico do original). 
usuários, o espaço-tempo da ação de linguagem, essa característica também está presente na metafunção interpessoal, uma vez que, ao interagir com um interlocutor, é necessário analisar o espaço-tempo em que a interação está acontecendo para que os papéis dos usuários sejam atribuídos de maneira eficiente.

Por fim, a metafunção textual na LSF pode ser relacionada ao aspecto verbal no ISD, na medida em que trata das escolhas que o falante tem à sua disposição para construir a mensagem, ou seja, refere-se ao que ele traz consigo de conhecimento sobre a língua.

No tocante à abordagem do texto como principal unidade de análise, também podem ser estabelecidas semelhanças entre as teorias focalizadas. Concordando com estudos da LSF, no que se refere aos textos, Bronckart (2013: 68) afirma que, metodologicamente, "o texto é a principal unidade de análise, porque é o texto como um todo que dá sentido à atividade verbal. Além disso, o texto organiza as correlações entre os subsistemas de estruturação linguística (morfossintática, lexical e fonológico)" (itálico do original) ${ }^{9}$.

Para o ISD, textos são "produções verbais efetivas, que assumem aspectos muito diversos, principalmente por serem articuladas a situações de comunicação muito diferentes" (Bronckart 2003: 69). Por estarem ligados a necessidades, interesses e condições funcionais das formações sociais onde são desenvolvidos, foram elaboradas diferentes formas de construir um texto. A preocupação com a delimitação e denominação dessa diversidade fez com que surgissem várias classificações, que têm como centro a noção de gênero de texto. Os gêneros, portanto, "são as várias maneiras culturalmente orientadas de construção e organização de significações (ou significados)" (Bronckart 2013: 68).

Sintetizando essas duas noções para o ISD, valemo-nos das palavras do próprio Bronckart (2003: 75):

Chamamos de texto toda unidade de produção de linguagem situada, acabada e auto-suficiente (do ponto de vista da ação ou da comunicação). Na medida

9. "the text is the major unit for analyses, because is the text as a whole that lends meaning to verbal activity. In addition, the text organises the correlations between the sub-systems of linguistic structuring (morphosyntactic, lexical and phonological)" (Bronckart 2013: 68 ; itálico do original). 
em que todo texto se inscreve, necessariamente, em um conjunto de textos ou em um gênero, adotamos a expressão gênero de texto em vez de gênero de discurso (negrito do original).

Para o autor, os gêneros são múltiplos, podendo até ser em número infinito, mas os "segmentos" que os compõem têm número finito e podem "ser identificados por suas características linguísticas específicas". Esses segmentos são os discursos que, por suas regularidades na estrutura linguística, são considerados pertencentes "ao domínio dos tipos", por isso, o ISD os chama de tipos de discurso (Bronckart 2003: 75-76; itálico do original).

Os tipos de discurso, segundo o ISD, são quatro: interativo; teórico; relato interativo; e narração. Os dois primeiros referem-se ao mundo do expor e, os dois últimos, ao mundo do narrar. De acordo com Bronckart (2013 p. 75), "como uma regra, gêneros de texto são compostos por vários tipos de discurso, entre os quais um é geralmente dominante" ${ }^{10}$. Ou seja, cada tipo de discurso predomina em certos gêneros de texto. Por exemplo, o tipo narrativo é dominante em gêneros como novela, fábula, entre outros.

Numa tradicional vertente da LSF, é relevante considerar que é por meio da linguagem que os gêneros textuais se realizam, evidenciando traços dos contextos de situação e de cultura. "É por meio dos padrões discursivo-semânticos, léxico-gramaticais e fonológicos do código linguístico que o nível contextual do gênero é realizado ou expresso pela linguagem" (Eggins 2004: 64) ${ }^{11}$. Ainda segundo Eggins (2004), as diferentes formas de uso da linguagem, a partir de escolhas na léxicogramática, feitas pelo falante ou escritor para alcançar determinado objetivo, é o que pode ser definido como gênero.

A noção de tipos de discurso no ISD pode ser relacionada ao que é denominado de atividades sociossemióticas em Matthiessen, Teruya e

10. "As a rule, text genres are composed of several types of discourse, among which one is generally dominant" (Bronckart 2013: 75).

11. "Technically, we can see that it is through language that genres get realized. It is through the discourse-semantic, lexico-grammatical and phonological patterns of the language code that the contextual level of genre is realized through, or expressed, in language" (Eggins 2004, 65). 
Lam (2010: 95), numa vertente mais atual da LSF. Conforme os autores, "a atividade é o processo social e/ou semiótico em que os interactantes do contexto estão envolvidos" ${ }^{12}$. Considerando o princípio de que interagimos a partir de formas enunciativas construídas culturalmente e realizadas em textos, a denominação atividades sociossemióticas é justificada por representarem diferentes maneiras de agir mediadas pelos usos da língua, situados em contextos específicos. Matthiessen, Teruya e Lam (2010) apresentam uma tipologia textual baseada em contexto e configurada em oito processos sociossemióticos, a saber: expor; reportar; recriar; compartilhar; realizar; recomendar; habilitar; e explorar.

Consideramos esse ponto divergente entre as duas teorias, pois, por vezes, o que pode ser considerado como gênero na LSF (Escola de Sidney), para o ISD trata-se apenas de um tipo de discurso em determinado gênero de texto. Para exemplificar, Bronckart (2013) apresentou o texto de um estudante que, ao ser analisado por Martin (2009), foi descrito como um texto que se enquadra no gênero exposição. Porém, para o ISD, a exposição corresponde ao discurso teórico, que acontece dentro de um gênero argumentativo como o editorial ou artigo de opinião ${ }^{13}$.

No que se refere ao ensino da linguagem, também podemos encontrar aproximações entre o ISD e a LSF. No Interacionismo Sociodiscursivo é abordada a questão das capacidades de linguagem e a construção do modelo didático (cf.: Dolz, Gagnon \& Decândio 2010). Na Linguística Sistêmico-Funcional, é enfatizada, no Ciclo de Aprendizagem, a identificação das etapas e fases de um gênero (cf.: Gouveia 2014; Muniz da Silva 2014; Silva 2015).

O modelo didático, tendo como base a infraestrutura geral do texto, aparece como uma ferramenta para definir o objeto a ensinar e suas dimensões supostamente ensináveis. Assim, ele pode ser dividido em contexto físico e sociosubjetivo de produção (capacidade de ação),

12. "The activity is the social and/or semiotic process that the interactants in the context are engaged in" (Matthiessen, Teruya \& Lam 2010: 95).

13. Para mais detalhes sobre as concepções de gênero na LSF, consultar Motta-Roth e Heberle (2005), Silva e Espindola (2013) e Vian Jr e Lima-Lopes (2005). 
plano global (capacidade discursiva) e mecanismos de textualização e enunciativos (capacidade linguístico-discursiva).

O plano global diz respeito à forma como é organizado o conteúdo temático do texto. Em um artigo de opinião, por exemplo, temos a parte introdutória com a apresentação da tese, em seguida, os argumentos e, ao final, a conclusão em forma de avaliação ou solução. Isso equivale ao que fazem Martin e Rose (2008), ao definirem que o gênero exposição (equivalente ao artigo de opinião) pode ser composto pelas etapas: Tese, Argumentos e Reiteração.

No Quadro 3, sistematizamos uma comparação entre as concepções de texto e gênero textual nas teorias focalizadas neste artigo.

Quadro 3 - Aproximação entre texto, gêneros e tipo de discurso

\begin{tabular}{|c|c|c|}
\hline & $\begin{array}{c}\text { LINGUÍSTICA SISTÊMICO- } \\
\text { FUNCIONAL }\end{array}$ & $\begin{array}{l}\text { INTERACIONISMO } \\
\text { SOCIODISCURSIVO }\end{array}$ \\
\hline Texto & $\begin{array}{l}\text { O que dá sentido à atividade de } \\
\text { interação verbal. }\end{array}$ & $\begin{array}{l}\text { Produções verbais articuladas } \\
\text { a diferentes situações de } \\
\text { comunicação. }\end{array}$ \\
\hline Gêneros & $\begin{array}{l}\text { Definidos a partir de objetivos } \\
\text { sociais contextualizados. }\end{array}$ & $\begin{array}{l}\text { Formas orientadas culturalmente } \\
\text { de construção e organização de } \\
\text { significados. }\end{array}$ \\
\hline $\begin{array}{l}\text { Tipo de } \\
\text { discurso }\end{array}$ & - & $\begin{array}{l}\text { Segmentos linguisticamente } \\
\text { regulares constitutivos do gênero } \\
\text { textual. }\end{array}$ \\
\hline
\end{tabular}

Fonte: elaborado pelos autores com base nos principais autores das suas teorias

As definições de texto encontradas nas duas teorias são bem próximas. Em relação à noção de gênero, na abordagem sistêmico-funcional, há uma definição que pode ser equiparada à encontrada no ISD, uma vez que ambas refletem o contexto de produção e circulação do enunciado. A diferença encontrada, conforme demonstrado anteriormente, refere-se aos tipos de discurso, no ISD, ou gênero, na LSF. Os tipos de discurso do ISD podem ser enquadrados no que se compreende por gênero na perspectiva sistêmico-funcional da Escola de Sidney. 


\section{Considerações finais}

Realizamos uma análise comparativa entre alguns pressupostos teórico-metodológicos do ISD e da LSF, identificando aspectos de aproximações entre as teorias. Encontramos semelhanças na forma que ambas concebem a linguagem; em como veem a linguagem em uso (metafunções da linguagem e aspectos do contexto da ação de linguagem), bem como suas concepções de texto e gênero textual. Divergências foram encontradas na forma como as teorias linguísticas abordam a questão do tipo de discurso, pois há propostas na LSF que considera aspectos mais gerais, preocupando-se com os contextos situacional e cultural em que o texto é produzido e, portanto, com o gênero. Na LSF, há também a proposta de trabalho com as atividades sociossemióticas. Já o ISD considera aspectos mais específicos como os tipos de discurso constituintes do gênero.

Consideramos serem as duas teorias linguísticas importantes para o estudo da linguagem, uma vez que se preocupam com a língua em funcionamento e consideram as particularidades dos usuários. Mas não deixamos de lado algumas limitações, como, por exemplo, o que afirmam Silva e Espindola (2013) ao discutirem as formas pelas quais os gêneros textuais podem ser analisados na perspectiva da LSF. Os autores destacam o risco de as análises linguísticas, fundamentadas em perspectivas sistêmico-funcionais, limitarem-se apenas a aspectos mais formais da língua. Salientamos que esse risco não é descartado nos trabalhos que assumem a abordagem do ISD.

Ao apresentar alguns aspectos da LSF a partir do ponto de vista do ISD, Bronckart (2013: 81), com quem concordamos, afirma que, em um nível epistemológico, "as duas abordagens enfatizam a dimensão praxeológica da linguagem" (itálico do original) ${ }^{14}$. Em relação à metodologia, as duas teorias se baseiam em uma rigorosa análise de dados linguísticos, levando em conta sempre sua organização, sua produção contextualizada e sua organização em enunciados e estes em textos. Por fim, em um nível sociopolítico, os pesquisadores dessas tendências defendem a ideia da atividade científica voltada para o uso social,

14. "the two approaches lay emphasis on the praxeological dimension of language (...)" (Bronckart, 2013: 81; itálico do original). 
afinal, como o próprio Michael Halliday defende, é isso que define o valor de uma teoria.

\section{Agradecimento}

O segundo autor deste artigo agradece ao Conselho Nacional de Desenvolvimento Científico e Tecnológico (CNPq) pela bolsa de produtividade em pesquisa (PQ-2) concedida, contribuindo portanto para produção da pesquisa apresentada neste artigo (Processo 305094/2016-5).

Recebido em: 15/05/2017

Aprovado em: 30/07/2017

E-mail: alinymendes.uft@gmail.com wagnerodriguesilva@gmail.ccom paulodasilvalima@yahoo.com.br

\section{Referências bibliográficas}

BARbara, Leila; MACÊdo, Célia. 2009. Linguística sistêmico-funcional para a análise de discurso: um panorama introdutório. Cadernos de Linguagem e Sociedade. Brasília: UNB/PPGL, v. 1, n. 10, p. 89107.

Bork-Gödke, Ana Valéria. 2016. Produção Escrita de Gêneros Profissionais em Lingua Inglesa: vozes entrelaçadas no processo de escrita e reescrita textual. Tese (Doutorado em Estudos da Linguagem). Universidade Estadual de Londrina, Londrina.

BroncKart, Jean-Paul. 2003. Atividade de linguagem, textos e discursos: por um Interacionismo sócio-discursivo. Trad. Anna Raquel Machado, Péricles Cunha. São Paulo: EDUC.

2006. Interacionismo Sócio-discursivo: uma entrevista com Jean Paul Bronckart. Revista Virtual de Estudos da Linguagem - ReVEL. vol. 4, n. 6, p. 1-29. Tradução de Cassiano Ricardo Haag e Gabriel de Ávila Othero.

2013. The language system at the heart of the systems make up the human being. In: Gouveia, Carlos; Alexandre, Marta Filipe. Languages, metalanguages, modalities, cultures: functional and socio-discursive perspectives. Lisboa: BonD \& ILTEC. p. 65-84. 
Celani, Maria Antonieta. 1998. Transdisciplinaridade na Linguística Aplicada no Brasil. In: Signorini, Inês; Cavalcanti, Marilda (Orgs.). Linguística e Transdisciplinaridade. Campinas: Mercado de Letras. p. 129-142.

Chiapinotto, Diego. 2010. O Interacionismo Sociodiscursivo em Texto Didático de Leitura e Produção de Textos para a Educação Superior a Distância. In: Anais do Congresso Internacional de Filosofia e Educação. p. 1-15.

Dolz, Joaquim; Schnewly, Bernard. 2004. Gêneros e Progressão em Expressão Oral e Escrita - elementos para reflexões sobre uma experiência suíça (francófona). In: Dolz, Joaquim; ScHNEwLY, Bernard (Orgs.). Gêneros Orais e escritos na escola. Campinas: Mercado de Letras. p. 41-70.

; Gagnon, Roxane; Decândio, Fabrício. 2010. Produção escrita e dificuldades de aprendizagem. Tradução Fabrício Decândio e Anna Rachel Machado. Campinas: Mercado de Letras.

EgGINs, Suzanne. 2004. An Introduction to Systemic Functional Linguistics. 2nd. Ed. London: Continuum.

Fabrício, Branca. F. 2006. Linguística Aplicada como espaço de "desaprendizagem" - redescrições em curso. In: MoITA LOPES, Luiz Paulo (Org.). Por uma Linguística Aplicada Indisciplinar. São Paulo: Parábola Editorial. p. 45-65.

Fuzer, Cristiane; CABRAL, Sara. 2010. Introdução à Gramática SistêmicoFuncional em Língua Portuguesa. Santa Maria: Universidade Federal de Santa Maria, Centro de Artes e Letras, Departamento e Letras Vernáculas, Núcleo de Estudos em Língua Portuguesa.

Gonçalves, Adair; Silva, Wagner; Góis, Marcos. 2014. Introdução - Múltiplas vozes na construção de objetos de investigação na Linguística Aplicada. In: Gonçalves, Adair; Silva, Wagner; Góis, Marcos (Orgs.). Visibilizar a Linguística Aplicada: abordagens teóricas e metodológicas. Campinas: Pontes Editores. p. 13-23.

Gouveia, Carlos. Compreensão leitora com base instrumental do ensino da produção escrita. In: Silva, Wagner; SAntos, Janete; Melo, Márcio (Orgs.). Pesquisas em língua(gem) e demandas do ensino básico. Campinas: Pontes Editores. p. 203-231.

Habermas, Jürgen. 1987. Théorie de l'agir communicational, t. I et II., Paris, Fayard.

Halliday, Michael. 1985. An Introduction to Functional Grammar. London: Arnold. 
; Hasan, Ruqaiya. 1989. Language, Context, and Text: aspects of language in a social-semiotic perspective. Oxford: Oxford University Press.

; . 2006. Retrospective on SFL and literacy. In: WhITTAKER, Rachel; O'Donnell, Mick; McCABE, Anne (Eds.). Language and Literacy. London: Continuum. p. 15-44.

; Matthiessen, Christian. 2014. An Introduction to Functional Grammar. Hodder Education.

Kumaravadivelu, B. 2005. Deconstructing Applied Linguistics: a postcolonial perspective. In: FreIre, Maximina; Abrahão, Maria Helena; Barcelos, Ana Maria (Orgs.). Linguística aplicada \& contemporaneidade. Campinas: Pontes/ALAB. p. 25-37.

Martin, J. R.; Rose, David. 2008. Genre Relations: Mapping Culture. London: Equinox.

Matthiessen, Christian; Teruya, Kazuhiro.; Lam, Marvin. 2010. Key terms in Sistemic Funcitional Linguistics. London and New York: Continuum International Publishing Group, 2010.

Moita Lopes, Luiz Paulo. 1998. A transdisciplinaridade é possível em Lingüística Aplicada? In: Signorini, Inês; Cavalcanti, Marilda (Orgs.). Linguística e transdisciplinaridade. Campinas: Mercado de Letras. p. 113-128.

Motta-Roth, Désirée; Heberle, Viviane. 2005. O conceito de "estrutura potencial do gênero" de Ruqayia Hasan. In: Meurer, J. L.; BoninI, Adair; Мотта-Rотн, Désirée (Orgs.). Gênero: teorias, métodos, debates. São Paulo: Parábola Editorial. p. 12-28.

MunIZ DA SiLVA, Edna. 2014. Leitura e produção de gêneros textuais na escola. In: Silva, Wagner; Santos, Janete; Melo, Márcio (Orgs.). Pesquisas em língua(gem) e demandas do ensino básico. Campinas: Pontes Editores. p. 233-260.

Painter, Clare; Martin, J. R.; Unsworth, Leon. 2013. Reading Visual Narratives: Image Analysis of Children's Picture Books. Bristol: Equinox.

Pennycook, Alastair. 2001. Critical Applied Linguistics: A Critical Introduction. London: Routledge.

Ricoevr, Paul. 1986. Du texte à l'action; essais d'herméneutique II. Paris, Seuil.

Signorini, Inês. 1998. Do residual ao múltiplo e ao complexo: o objeto da pesquisa em Linguística Aplicada. In: Signorini, Inês; CaVAlCANTI, Marilda (Orgs.). Linguística e transdisciplinaridade. Campinas, SP: Mercado de Letras. p. 99-110. 
Silva, Cícero; Silva, Wagner. 2016. Análise linguística no ensino de língua materna: uma abordagem sistêmico-funcional. Calidoscópio. São Leopoldo: UNISINOS, v. 14, n. 3, p. 377-389.

SiLvA, Wagner. 2014. Gêneros em práticas escolares de linguagens: currículo e formação do professor. Revista Brasileira de Linguística Aplicada. Belo Horizonte: UFMG, v. 15, n. 4, p. 1023-1055. ; SiLva, Cícero et al. 2015. Linguística sistêmico-funcional da sala de aula. Raído. Dourados: UFGD, v. 9, n. 18, p. 137-172.

; Espindola, Elaine. 2013. Afinal, o que é gênero textual na Linguística Sistêmico-Funcional? In: Revista da ANPOLL. v. 1, n. 34, p. 259-307.

; Brito, Cristiane; Martins, Renato; Santos, Sandra. 2017. Como formadores e alunos da licenciatura em Letras compreendem a linguística aplicada? Revista Brasileira de Linguística Aplicada. Belo Horizonte: UFMG, v. 17, n. 1, p. 31-60.

; SiLva, Kellen; BorbA, Lucieny. Construção da reflexão na escrita acadêmica por professores em formação inicial. Revista Brasileira de Linguística Aplicada. Belo Horizonte: UFMG, v. 16, n. 2, p. 277308.

VIAN JR., Orlando. 2013. O ensino de inglês instrumental para negócios, a linguística sistêmico-funcional e a teoria de gênero/registro. The ESPecialist. São Paulo: PUC, v. 24, n. 1, p. 1-16.

; IKEDA, Sumiko. 2009. O ensino do gênero resenha pela abordagem sistêmico-funcional na formação de professores. Linguagem \& Ensino, Pelotas: UCPel, v.12, n.1, p. 13-32.

; LiMA-LoPES, Rodrigo. 2005. A perspectiva teleológica de Martin para a análise dos gêneros textuais. In: Meurer, J. L.; Bonini, Adair; MoтtA-Roth, Désirée (Orgs.). Gênero: teorias, métodos, debates. São Paulo: Parábola Editorial. p. 29-45. 